\title{
Metanarrativa da memória em conflito com o relato: o testemunhal e as imagens no documentário Homem comum
}

\author{
Thiago S. Venanzoni*
}

\author{
Homem comum (Brasil, 2015, 84 minutos) \\ Direção, roteiro e produção: Carlos Nader \\ Fotografia: Carlos Nader, Fernando Laszlo, Vitor Civita \\ Montagem: Carlos Nader e Alexandre Braz \\ Produção executiva: Flávio Botelho e Kátia Nascimento \\ Produção: Já Filmes \\ Distribuição: Vitrine Filmes \\ Elenco: Nilson, Nilseane, Carlos Nader, Jane e Liciane
}

Em 1996, o cineasta Carlos Nader consegue, por meio de edital, a verba para a produção de um documentário em que a proposta não previa um destino, apenas indicava um caminho. A ideia era chegar com uma câmera em postos de gasolina que se localizariam às margens das estradas e pedir para aqueles caminhoneiros, que paravam nesses lugares por motivos diversos, a seguir viagem com eles. A partir disso, Nader iniciaria um método de diálogo para chegar ao seu sentido inicial em torno do filme: a de perguntar coisas triviais, como por exemplo, se é difícil viajar tantas vezes em pouco tempo ou se o ofício na estrada se faz a partir de muito cansaço, entre outras montagens e narrativas do cotidiano daqueles motoristas. Entretanto, em algum momento dessa conversa, e a proposta, assim, se completaria, Nader perguntaria: você já se olhou no espelho alguma vez e se perguntou, "o que é a vida? O que estou fazendo aqui neste momento?". Seria ali um exercício de memória e deslocamento, alterando o curso que se encaminhava o relato a partir das perguntas feitas às personagens. A intenção de Nader é que dentre as perguntas triviais e simples houvesse algo inscrito numa relação ontológica, estabelecida na metafísica, e que essa imagem trazida pela palavra pudesse aproximar o interlocutor de alguma forma à condição existencial que a memória realoca os sujeitos em sua dinâmica. Entretanto, em pouco tempo o cineasta percebeu que isso não era algo em torno do agir e, por essa razão, não conseguiu sucesso em sua

* Doutorando. Universidade de São Paulo - USP, Escola de Comunicação e Artes - ECA, Programa de Pós-Graduação em Meios e Processos Audiovisuais PPGMPA. 03178-200, São Paulo, Brasil. E-mail: thiagovenanzoni@gmail.com 
Metanarrativa da memória em conflito com o relato: o testemunhal e as imagens no

intenção, apenas frases de negação. Era preciso, então, construir a imagem, a memória por meio de narrativas. Tudo isso ele relata em artifício muito utilizado nos documentários que é a voz off - no caso, do próprio Nader - e com imagens que já reconstroem uma lembrança, a do autor em sua montagem.

Ainda em sua intenção, e isso se realiza na montagem das imagens antigas, do ano de 1996, Nader chega em algo que desperta não a lembrança do interlocutor, mas a sua própria memória. Naquele momento, relata o cineasta do filme em uma conversa nos dias atuais com sua personagem, estava bastante mobilizado por um filme dinamarquês de Carl T. Dreyer, um dos grandes autores de cinema da história. A palavra, como ficou traduzido em língua portuguesa, trata, de forma bem simplificada aqui dita, da força da palavra. Podemos dizer, igualmente de forma livre, se o filme de Dreyer tematiza a palavra, o filme de Nader tematiza a imagem e a potência da memória. E no lance de dados da memória surge a imagem do filme a Nader ao conversar com Nilson, caminhoneiro que responde acenando ao positivo: "sim, já pensei nisso sim". O filme, o antigo, do edital, e esse que viria a ser o filme oficial, Homem comum, passa então a não ser mais algo sobre a vida dos caminhoneiros, mas a vida de Nilson, e de Nader.

A câmera e, logo, o filme, passaram então a seguir os caminhos de Nilson ainda naquele filme originalmente pensado. Carlos Nader, numa conversa com sua personagem, Nilson, enquanto as imagens das estradas do caminhão passam na tela para o espectador, explica o contexto daquelas imagens e a razão em que se pôs em contato com seu filme: a mnemosine, ou seja, a própria relação entre as memórias e imagens que surgem inesperadamente. A crença de Nilson pela palavra proferida por Nader trouxe a lembrança do filme de Dreyer ao realizador, de forma imediata. Em função disso, o filme se coloca em disposição das imagens da memória trazidas ao longo de quinze anos de gravações. Não se trata apenas em afirmar que a montagem se coloca em uma condição não narrativa, ainda que seja uma questão estruturalista que pode ser pensada conjuntamente, mas as imagens que se comportam em diálogos mútuos, seja com outras imagens ou mesmo contrariando relatos, e possibilitam uma metanarrativa que opera como o trauma da memória: as imagens não lembradas que reaparecem fora do relato usual do documentário. Não mais a palavra tem a força, como em Dreyer, mas a imagem dimensiona a potência documental do filme. Ou, se a palavra é incorruptível no filme do cineasta dinamarquês, seria a imagem o que resiste no filme de Nader, assim como o conceito de memória em certa visada. Não há contradição, nem para a memória: imagem e palavra se ligam sem contrariedades. 
Homem comum, portanto, remonta duas camadas documentais que se colocam em conflito. O relato documental do testemunho que seria a verdade que acomoda a lembrança consciente das personagens postas, Nilson, sua filha Nilseane, a mãe de sua filha, que morre nesse tempo, e a segunda esposa, e seu contraponto, as imagens de arquivo dos quinze anos de registro dessa relação entre o filme e Nilson. Em certa medida, o filme remonta o atual conflito estético dos documentários, os vendo como um campo ou um gênero. Ao menos no Brasil, por meio de filmes de Arthur Omar e Eduardo Coutinho, coloca-se o gênero em suspensão ao debater o registro documental como uma encenação, tal como o outro campo categorizado como o seu oposto, o da ficção ou ficcional. Coutinho fazia de seus filmes, os encarando aqui como uma grande obra, enunciação do próprio jogo, logus, explicitando, em muitos casos, o teor ficcionalizante dos documentários. O caso mais emblemático desse efeito intencional se encontra no filme Jogo de cena, de 2006, em que o palco dá vez a encenação travestida de real.

O que nos remete ao que o teórico Roger Odin (2012) nomeou como uma condição da leitura. De forma sintetizada aqui neste artigo, podemos definir que a questão de Odin não estaria em pensar em categorização desses gêneros, sendo ele um filme de ficção ou documental, mas pensar em como o espectador se engaja com a narrativa, trazendo ele ao campo do real representado ou como o engano da ficção, ou, como ele apresenta, o leitor construtor de um eu-origem fictício, no caso da leitura fictivizante, ou o leitor construtor de eu-origem real, na leitura documentarizante. Em outro momento ele vai radicalizar essas categorias, mas não abandoná-las. Para nosso propósito momentâneo, nos serve pensar juntamente com ele a partir dessa primeira abordagem. Dessa maneira, podemos lançar como hipótese que o emblema posto pelo filme de Nader se dá também em torno do embate da referencialidade: de que real falamos, afinal? Será que é possível capturar esse real apenas tendo a narrativa como possibilidade?, nos pergunta o filme nas entrelinhas. Por meio dessas perguntas, o filme parece construir seu jogo entre narrativas: uma narrativa que opera a leitura documentarizante em que o real se coloca, com todo o seu logus afetivo de chamamento do leitor, e uma metanarrativa que desmente a narrativa principal. Nos parece o mesmo jogo da memória e da lembrança, como abordaremos, e que nos assegura um caminho que Nader opta para justificar suas escolhas.

Dentro desse contraponto das narrativas de Homem comum é posto uma verdade, a própria realidade, e seu contrário simbólico, das imagens que apresentam outro modo de construir a narração, tal como a memória, ou o sonho. O discurso onírico, em certa análise, opera em outro registro, que se aproxima dos símbolos sem significações precisas, mais como um significante vazio, ou 
Metanarrativa da memória em conflito com o relato: o testemunhal e as imagens no

perdido. Portanto, as imagens estariam, nesse filme mais no campo do simbólico, ou seja, do que escapa ao relato e à narrativa do comum. Mas nunca à memória, ela mesma, pois essa surge, reaparece, e não se permite totalmente à consciência. Se para Freud os sonhos podem ser encarados como aquilo que escapa a uma narração do comum, ou seja, tem que ser observado a partir do simbolismo que eles traduzem à consciência ${ }^{1}$, a memória, igualmente, se coloca como um discurso completo em sua falha. Não se trata, necessariamente, como um pouco antes dito, não haver uma narrativa que comporte o simbólico emergido da memória, ou mesmo do sonho, ela existe e pode ser denominada como imagens-narrativa.

Assim como no filme de Carlos Nader, a imagem da memória, em análise aqui empreendida, coloca uma narrativa em conflito à chamada narrativa do comum. O homem comum é desfeito em imagens-narrativa, na metanarrativa, que o localiza em outro lugar, fora do testemunhal. Em algo mais próximo de um real, ainda que longe do referencial. Eis o contraponto. Tal como a memória em sua formulação psíquica, dirá Freud, as imagens trazidas pela montagem reinserem algo que não podia ou devia ser esquecido, e são trazidas à tona como uma lembrança inesperada. O relato, em sua oposição, se assemelha às lembranças encobridoras, aquela que barra a aproximação com a lembrança do trauma, com o núcleo psíquico. Há uma possibilidade conceitual em Freud que se encontra na nomeação de uma dialética entre lembrança e esquecimento, ou seja, aquilo que se torna possível buscar como esquecimento pois uma lembrança encobridora foi localizada.

As imagens que vão e vem, imagens antigas que ressurgem, imagens recentes que encenam um diálogo com a imagem de antes. As imagens do filme de Carl Dreyer que entram em concordância com as imagens postas como parte da vida de Nilson. O que chamamos aqui de imagens-narrativa e se esclarecem no filme como uma metanarrativa se aproxima da memória, sobretudo, por se tratar de imagens e de algo que retorna sem o consentimento do sujeito ali posto como personagem. Há uma aproximação em torno das formas dessas imagens, que se referem à memória temetizada no filme, como os frames abaixo.

1. E não por acaso a definição do inconsciente e a fundação da psicanálise como um campo clínico e filosófico são encontradas na celebre obra A interpretação dos sonhos (edição mais recente no Brasil pela L\&PM Pocket, 2012), de 1901. 


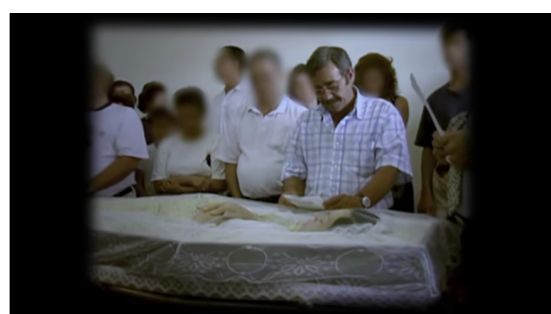

Figura 1

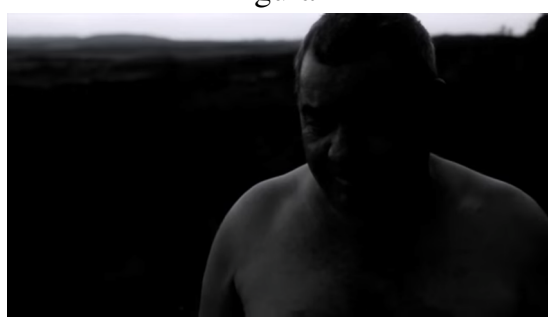

Figura 3

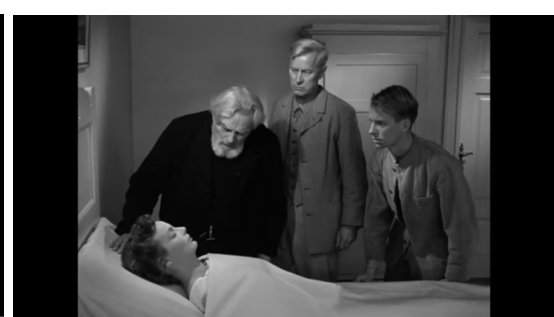

Figura 2

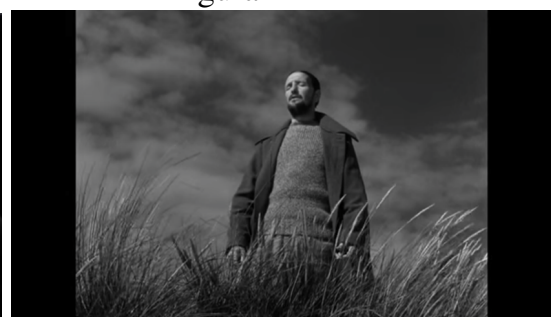

Figura 4

Figura 1 e Figura 3. Imagem de arquivo do enterro da mulher de Nilson e imagem de Nilson.

Figura 2 e Figura 4. Recortes de dois momentos do filme de Carl T. Dreyer.

$\mathrm{O}$ que as imagens localizam nesse filme em torno de uma memória que se traduz em narrativa é semelhante à imagem que Benjamin revisita para uma crítica em torno da obra Em busca do tempo perdido, de Marcel Proust, o que ele denominou de "trabalho de Penélope da reminiscência"(Benjamin, 2012, p.39). A personagem feminina de A Odisseia, que vive a tecer à espera de Ulisses, seu amor, é o que Proust faz, na análise do filósofo alemão, e, em certa medida, Nader tenta reconstruir como um método em sua metanarrativa: os fios da memória que traduzem em um tecido material, poético. Justamente por falar em memória, reminiscência como produto da narração, Benjamin denomina Em busca do tempo perdido como uma autobiografia de Marcel Proust. Em igual medida, Homem comum se trata de uma autobiografia do seu realizador ao passo que o trabalho de tecer os fios memorialisticos são materializados em imagens montadas que se consomem, dialogam entre si, descrevem um outro lugar e se distanciam do relato testemunhal, a partir de uma narração da memória dos quinze anos de duração desse processo no qual as imagens conseguem expor.

Se considerarmos um início, Homem comum começa em uma conversa entre Nilson e sua filha, Nilseane. Mas o começo se dá antes disso, e já está, nessa perspectiva que o filme nos traz em seu discurso. A conversa se dá à 
Metanarrativa da memória em conflito com o relato: o testemunhal e as imagens no

documentário Homem comum

beira de um riacho, forjando a cena de um piquenique. Trata-se de um fingimento, sobretudo, pois a imagem nos diz: os elementos do piquenique, suco, pães, estão intactos; e a intervenção do documento aparece a todo momento, seja pela indicação do realizador, Carlos Nader, ao que eles devem dizer em dado momento da conversa, ou mesmo o microfone externo que é focalizado pela câmera, registrando os relatos de ambos. Os dois estão falando amenidades, até aquele momento sem ruídos, apenas dizem um pouco da vida de cada um. Mas algo não dito aparece, e assim podemos pensar novamente na memória e o incomodo também: Nilson muda a conversa e reclama com a filha de determinado comportamento dela e a criação de sua neta, Nilseane retruca e não concorda. Evidencia um paradoxo do pai e nesse ritmo o relato é construído. Em algum momento uma lembrança toma conta da conversa do pai e surge como argumento. Nilson diz: "Como nunca te dei nada, Nilseane? E aquele tecladinho, você esqueceu? Você adorava aquilo". Em uma condição conflituosa, Nilseane retruca: "Que teclado, nem sei o que é isso. Não me lembro!"

Aqui se estabelece o conflito que, na verdade, é o conflito narrativo já comentado que o filme se propõe. As lembranças encobridoras que tentam ocultar o simbólico que emerge na imagem da memória. As imagens do filme nos esclarecem que na infância a relação entre pai e filha era conduzida por outro afeto, distinto aquele que o referencial do diálogo nos determina à beira do riacho no piquenique encenado.

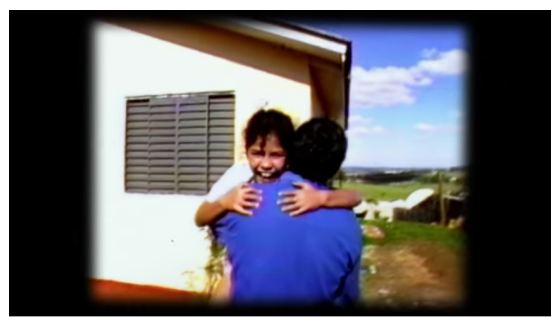

Figura 5

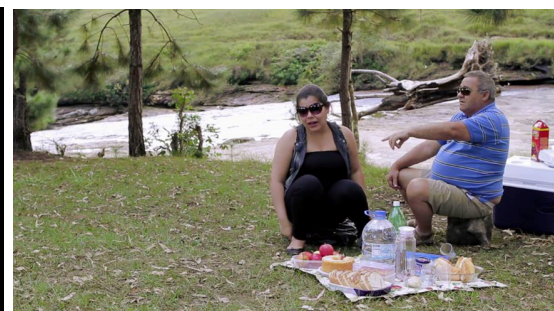

Figura 6

Figura 5. Nilseane criança encontra o pai que chegou.

Figura 6. Nilson e Nilseane hoje em dia.

Percebemos então, pelas imagens, a lembrança surgida que a consciência tenta se desfazer. Estabelecendo em narrativas, pois se trata de um filme, e não da própria estrutura psíquica do sujeito, ainda que a forje, a narrativa do relato documental é interrompida pela narrativa da imagem, construindo uma dialética (já mencionada em Freud, da lembrança e do esquecimento). 
Em outra passagem apresentada pela narrativa construída pelas imagens é mostrado o momento em que Nilseane, na infância, toca o teclado que o pai teria a presentado. Confessa, em seu momento infantil, que todos os amigos da escola onde ela estuda a consideram talentosa e, feliz, como demonstra a imagem, diz que irá tocar profissionalmente e ganhar muito dinheiro. Com isso poderá comprar caminhões para seus pais e amigos e todos poderão trabalhar como seu pai. Não se trata em dizer, de forma até bastante grosseira, que o relato referencial é desmentido pela imagem e a intenção do narrador seria a de desmascarar suas personagens. Ainda que nos leve a pensar nisso, o filme constrói o conflito de narrativas em outra ordem, explorando mais a questão da memória e como a imagem surge ao espectador para oferecer a representação de uma dialética já mencionada. Há uma encenação bastante clara, mesmo que sem intenção das personagens do jogo discursivo, do que chamamos aqui de narrativa referencial, do relato, e a metanarrativa das imagens e, portanto, se torna complicado seguir por uma chave crítica mais objetiva.

Para Benjamin, na obra de Proust, a lembrança nunca se esclarece numa clarividência precisa, ao contrário, é sempre uma imprecisão da semelhança que se localiza em "mundos dos sonhos, em que os acontecimentos não aparecem jamais como idênticos, mas sempre como semelhantes impenetravelmente semelhantes entre si"(Benjamin, 2012: 40). Diante desse modo de descrever, o filósofo alemão nos faz pensar nas narrativas do filme em questão aqui. As imagens, que trazemos como partida estarem na ordem simbólica, como já dito, transcrevem uma semelhança imprecisa que constrói uma tensão com o relato descrito pelas personagens. Enquanto há alguma ordenação razoavelmente clara na forma de narrar do testemunhal, haveria, nas imagens, o ruído necessário para interromper o fluxo normativo que o documentário como espaço da referencialidade tenta operar como gênero. Isso fica mais evidente quando o sonho se constrói como tema, e Nader pergunta a Nilson: "você sonha?". A resposta vem como uma negativa, ainda que Nader insista com as imagens. Apresenta a personagem dormindo e um ruído onírico se mostra na encenação do quadro, além de imagens do filme de Carl. T. Dreyer que entra em diálogo na construção dessa narrativa próxima ao onirismo. O sonho, a memória, e a imagem estariam em mesmo registro em Homem comum. Vale também comentar as marcações sonoras das imagens que o filme constrói. Em todo o momento as imagens antigas, que se apresentam na narrativa como imagens da memória, são apresentadas por uma encenação sonora ruidosa, que posiciona o espectador em sua condição simbólica.

A imagem-narrativa, nomeação possível ao que consideramos potência desse filme, teria como opacidade discursiva enunciar o dado da memória e, 
Metanarrativa da memória em conflito com o relato: o testemunhal e as imagens no

como já anteriormente lembrado, tematizar a memória como imagem incauta e provocadora, em certo sentido. Um breve instante de saída de um dado fluxo contínuo da vida, de uma temporalidade normartizadora que rege à realidade cotidiana, E uma aproximação de um campo onírico, da ordem do simbólico. Não à toa, tanto a filosofia estética aqui trazida na figura de Benjamin, quanto a psicanálise de linha freudiana, aproximam a imagem da memória com o sonho. Em certo aspecto, e outras leituras podem nos auxiliarem nesse campo, todas operam na ordem não-narrativa, mais difusa, objeto desejante que os surrealistas traduziram em manifesto e em materialidade da arte. Portanto, ao pensar em imagem, memória e sonho, não é semelhante a dizer que se trata de algo fora do tempo, mesmo sendo possível essa afirmação. Mas é preferível pensar que elas estejam em outro registro temporal, ou, em outra temporalidade.

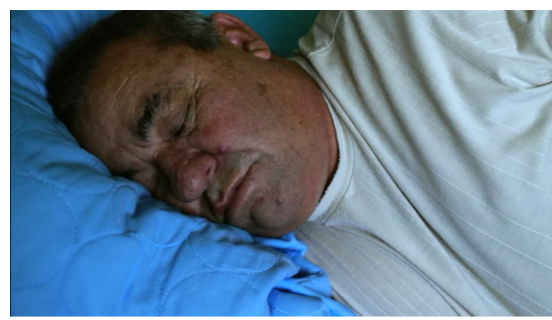

Figura 7. Frame de Nilson dormindo.

Aby Warburg, não sem razão (e o tempo nos mostra), nos faz refletir ao encontrar na imagem da arte do renascimento, o objeto mais observado por ele, um condensado de tempos que se movimentam e se encontram nas formas da própria imagem. Se pudermos, como outros comentadores do teórico alemão, ampliar essas observações por ele feitas e pensar nas narrativas das imagens como um pressuposto instaurado, sejam as imagens materiais ou as imagens mentais que a oralidade, apenas para citar como exemplo, provoca, chegamos ao tempo da imagem da memória e à temporalidade que Homem comum quer nos traduzir.

Essa temporalidade não seria o tempo cronológico, mas um tempo que imprime um passado no relato presencial. O aparato cinematográfico, e as imagens, nesse caso, seriam o próprio tempo localizado desse filme; não o tempo dito, mas um tempo experenciado. Walter Benjamin tem uma imagem bastante convincente sobre esse tempo suspenso que consideramos aqui, colocada por ele como um tempo espectral. Ou seja, a imagem que se torna viva diante de nós, como a da memória, nos coloca diante de um tempo compri- 
mido, achatado, que não é mais o presente, nem somente o passado. Trata-se de um tempo sem local definido, por isso, suspenso.

O filósofo francês George Didi-Huberman constrói em sua tese sobre Warburg um profundo diálogo estabelecido pelas ideais do teórico da imagem e a psicanálise freudiana. A imagem para Warburg, a partir desse descritivo crítico praticado por Didi-Huberman, tem laços reencontrados com o tempo. Não o tempo presente, propriamente, mas um tempo suspenso. Aqui nos é permitido pensar - e acreditamos que o filósofo francês tenha refletido nesse trajeto em Benjamin novamente, quando trata da questão da temporalidade em que a memória nos realoca; a imagem propriamente dita. "Portanto, a graça da imagem provoca, além do presente que ela nos oferece, uma dupla tensão: com respeito ao futuro, pelos desejos que convoca, e com respeito ao passado, pelas sobrevivências que evoca"(Didi-Huberman, 2013: 277). Em sua descrição nos traz a imagem de um turbilhão como se pensássemos, a partir disso, em "remoinhos do tempo na história"(ibid.: 277) que a imagem nos coloca diante. A descrição de Didi-Huberman sobre um prisma para se pensar Warburg nos atenta que não apenas o trajeto freudiano do conceito de sintoma

permite compreender melhor o poder desses remoinhos, sua necessidade dinâmica e formal, como também a metapsicologia freudiana do tempo permite observar o próprio rio, o rio das sobrevivências - o rio da Mnemosine - como que por dentro (ibid.: 278).

Ainda que controverso em alguns pontos, e mesmo que esse encontro nunca tenha ocorrido de modo formal, o filósofo francês aproxima a psicanálise de linha freudiana com os relatos warbuguianos para construir uma ideia, que nos parece bastante original, da imagem a partir de uma temporalidade, do seu retorno:

Melhor que o eterno retorno nietzschiano (a montante), a repetição freudiana (a jusante) permite captar com precisão o que Warburg procurava na temporalidade "sismográfica"e "dinamográfica"das imagens. O que Mnemosine almeja está justamente "além do princípio do prazer": não é a simples beleza, não é a rememoração como tal, e sim o próprio modo de instauração do tempo na imagem. (ibid.: 277, grifo do autor).

Na descrição do próprio Aby Warburg, o seu Atlas Mnemosine, trabalho de uma vida toda em que colecionou imagens da arte, de toda ordem, para mostrar uma simetria em suas formas, "poderia se designar como uma tentativa de introjeção na alma dos valores expressivos pré-formados na representação da vida em movimento" (Warburg, 2015: 365). Contudo, haveria nesse modo de notar a imagem em Warburg, por meio de uma repetição constante das formas, que expressam uma temporalidade que se distancia a da própria historiografia 
Metanarrativa da memória em conflito com o relato: o testemunhal e as imagens no

documentário Homem comum

da arte, como uma herança. Não um determinismo, como proporia alguns críticos, mas uma pré-formulação, como já dito.

Warburg crê, dessa forma, dizemos nós, que a imagem tem na gênese do seu próprio devir a condição de registrar uma certa figuração do que nomeou phobos, ou, a fantasia, e, por outro lado, fazer emergir uma certa racionalização no ato de sua construção. Os dois movimentos em uma mesma configuração. E por isso a permanência dessa imagem é uma condição, o seu post mortem, a sua existência como fantasma. No caso da imagem da memória, e da lembrança que encobre o trauma, nos parece a mesma condição de existência. Há uma volta delas pois esse movimento não é superado pela consciência, ele subscreve em outro lugar, e diz desse outro espaço construído. Para ser bastante freudiano, ela diz nessa outra cena. E é justamente nesses dois pontos que o filme enuncia as suas narrativas. Uma cena testemunhal, que relata as personagens a partir do que elas dizem, de suas lembranças da consciência, e a outra cena, o inconsciente, nomeado como a metanarrativa das imagens que abruptamente se apresentam para tensionar a narrativa do comum, colocá-la para fora do tempo em que ela afirma em sua intenção discursiva. Ou, podemos dizer com o auxílio de Aby Warburg, uma narrativa dimensionada pela razão crédula e outra da mnemosine. Como fantasmas, as imagens de Homem comum furam a narrativa possível do testemunhal, do relato do documentário, a sua referencialidade, e restabelecem o leitor em outro lugar no contato com o tempo; um tempo cronológico em conflito com o tempo das imagens.

Nos recolocamos, por fim, diante do retorno. As imagens voltam como uma memória esquecida que reaparece sem ao menos ser aguardada, e não necessariamente é compreendida. Em voz off, Nader confirma não saber a relação que a memória instaurou entre a imagem do filme dinamarquês, Nilson e o absurdo da vida. Pode-se afirmar que a metanarrativa ou a narrativa das imagens construída por Carlos Nader em Homem comum trata-se de um retorno, de uma condição traumática que mobiliza realizador e personagem a estar nesse filme durante o tempo de seu processo. Não se trata do tempo cronológico, e sim a condição de um tempo diante da imagem, da memória. Ao dado do relato testemunhal, Nader constrói longo percurso descritivo lembrando momentos em que a personagem se põe em relação com o filme, como na morte de sua esposa. Nader afirma: "naquele momento crucial da sua vida, você me chamou, mas você insistiu que eu fosse com uma câmera. Você convidou o filme pro enterro". O realizador afirma que esse convite foi crucial para o filme continuar, já que, explica a personagem, "o filme pegou sempre a gente". O que a câmera registrou, em certa análise, foi o que precisava ser esquecido, ou que é apenas uma lembrança encobridora, se pensarmos como 
Freud, e o dispositvo cinematográfico escancara. como faz a memória Nader então pergunta a Nilson: "o que esse filme fez com a gente, Nilsão?". A personagem se ausenta das palavras, cai em lágrimas. Não responde, mas a imagem diz. Pois não se trata da palavra dita que traz consigo o renascimento, como no filme dinamarquês em que a esposa morta se levanta pela crença à palavra dita, mas a imagem da esposa se levantando e a memória, que como um espectro, fantasma, se apresenta diante de nós e suspende o tempo, nos traz outra temporalidade, nos mobiliza, a exemplo do que ocorre nesse relato da personagem de Homem comum e no filme em sua construção narrativa das imagens. Nader afirma para Nilson: "precisamos desse filme para viver". Possível construir um paralelo ao sujeito que necessita da memória, da forma Marcel Em busca do tempo perdido.

\section{Referências bibliográficas}

Alloa, E. (org.) (2015). Pensar a imagem. Belo Horizonte: Autêntica Editora.

Benjamin, W. (2012). Magia e técnica, arte e política: ensaios sobre literatura e história da cultura (Obras Escolhidas v.1). São Paulo: Brasiliense.

Didi-Huberman, G. (2013). A imagem sobrevivente: história da arte e tempo dos fantasmas segundo Aby Warburg. Rio de Janeiro: Contraponto.

Freud, S. (2014). Conferências introdutórias à psicanálise (1916-1917), obras completas, vol. 13. São Paulo: Cia das Letras.

Freud, S. (1989). Primeiras publicações psicanalíticas (1893-1899), vol. III. São Paulo: Imago.

Machado, C.E.J.; Machado Jr., R. \& Vedda, M. (org.) (2015). Walter Benjamin: experiência histórica e imagens dialéticas. São Paulo: Editora Unesp.

Odin, R. (2012). Filme documentário, leitura documentarizante. Significação: Revista de Cultura Audiovisual, São Paulo, 37 (39): 10-30.

Xavier, I. (2008). O discurso cinematográfico: a opacidade e a transparência. São Paulo: Paz e Terra.

Warburg, A. (2015). Histórias de fantasmas para gente grande: escritos, esboços e conferências. São Paulo: Cia das Letras. 